PONTIFÍCIA UNIVERSIDADE CATÓLICA DO RIO DE JANEIRO

\title{
Uma avaliação econômica e financeira da Vale
}

\author{
BRUNNA NunEs CaVAlCANTE
}

Trabalho de Conclusão de Curso

Centro de Ciências Socials - CCS DEPARTAMENTO DE AdMINISTRAÇÃO Curso de Graduação em Administração 


\section{Uma avaliação econômica e financeira da Vale}

\section{Trabalho de Conclusão de CuRso}

Trabalho de Conclusão de Curso, apresentado ao programa de graduação em Administração da PUC-Rio como requisito parcial para a obtenção do titulo de Bacharel em Administração.

Orientador: Nelson Dabul 


\section{Resumo}

Cavalcante, Brunna. Dabul, Nelson. Uma avaliação econômica e financeira da Vale. Rio de Janeiro, 2015. 46 páginas. Trabalho de Conclusão de Curso - Departamento de Administração. Pontifícia Universidade Católica do Rio de Janeiro.

O propósito desse estudo é realizar uma análise financeira da empresa Vale S.A. buscando determinar o preço justo de suas ações. O trabalho foi realizado a partir de pesquisa utilizando dados secundários, que serviram de base para projeções que possibilitaram a determinação do valor da empresa pelo método de fluxo de caixa descontado.

Palavras- chave

Valuation, Vale, Avaliação de empresa, VALE3 


\section{Abstract}

Cavalcante, Brunna. Dabul, Nelson. Uma avaliação econômica e financeira da Vale. Rio de Janeiro, 2015. 46 páginas p. Trabalho de Conclusão de Curso - Departamento de Administração. Pontifícia Universidade Católica do Rio de Janeiro.

The purpose of this study is to conduct a financial analysis of the company Vale Inc. seeking to determine the real price of its. The study was conducted from research using secondary data, which were the basis for projections that enabled the determination of the value of the company by the discounted cash flow method.

\section{Key-words}

Valuation, Vale, enterprise valuation, VALE3 
Agradecimentos:

Agradeço primeiramente a minha família pela dedicação ao longo de todos esses anos. Aos meus amigos pelo apoio e incentivo. Ao meu orientador e professor Nelson Dabul pela paciência, esforço e ajuda que permitiram concluir esse trabalho. E por último e mais importante a Deus e sua Sagrada Família por toda ajuda e força em todos os momentos. 


\section{Sumário}

1 O Tema e o problema de estudo 1

1.1. Introdução ao tema e ao problema de estudo 1

1.2. Objetivo do estudo 3

1.3. Objetivos intermediários ao estudo 4

1.4. Delimitação e foco do estudo 4

1.5. Justificativa e relevância do estudo 5

2 Revisão de literatura e referencial teórico 6

2.1. O valor da empresa 6

2.1.1. Modelo de fluxo de caixa descontado (FCD) 7

2.1.2 Fluxo de caixa livre (FCL) 8

2.1.3. Custo médio ponderado de capital (WACC) 11

$\begin{array}{ll}\text { 2.3. Outros métodos de avaliação } & 14\end{array}$

3 Métodos e procedimentos de coleta e de análise de dados do estudo 15

3.1. Etapa de coleta de dados 15

3.2. Fontes de informações selecionadas para coleta de dados 15

3.3. Procedimento e instrumentos de coleta de dados 16

3.4. Formas de tratamento e análise dos dados coletados 16

$\begin{array}{ll}\text { 3.5. Limitações do método } & 16\end{array}$

4 A empresa 18

4.1. Missão, visão e valores $\quad 21$

4.2. Composição acionária $\quad 21$

4.3. Análise do mercado 22

4.4. Evolução do preço 23

5 Apresentação e análise dos resultados 25

5.1. Premissas utilizadas 25

5.2. Projeções 26

5.3. Custo do capital próprio (CAPM) 30 
5.4. Custo do capital médio ponderado (WACC)

6 Conclusões e recomendações para novos estudos

7 Referências bibliográficas 


\section{Lista de figuras}

Figura 1: Valor das ações da Vale em 25/06/2015 ….................................... 3

Figura 2: Áreas de atuação da empresa Vale................................................ 19

Figura 3: Produção da Vale em 2014 ........................................................... 22

Figura 4: Histórico do preço do minério de ferro .............................................. 24

\section{Lista de Tabelas}

Tabela 1: Composição acionária da empresa Vale em 30/12/2014 .................. 21

Tabela 2: Receita operacional bruta por área do minério de ferro .................... 26

Tabela 3: Volume histórico do minério de ferro ............................................ 27

Tabela 4: Projeção do preço do minério de ferro .......................................... 27

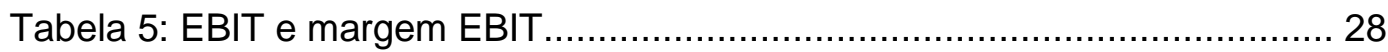

Tabela 6: Projeções EBIT e margem EBIT .................................................. 29

Tabela 7: Capex protejado (em milhões) ……........................................... 30

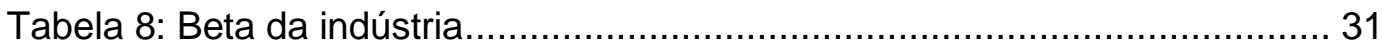

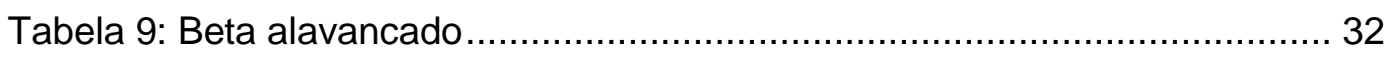

Tabela 10: Taxa livre de risco e prêmio de risco .......................................... 33

Tabela 11: Custo capital próprio................................................................... 35

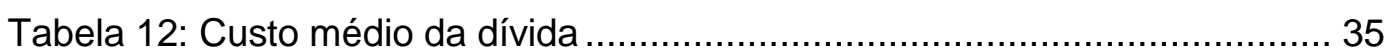

Tabela 13: Valor das ações e ADRs da Vale em 30/12/2014 .......................... 36

Tabela 14: Indicadores de endividamento ..................................................... 37

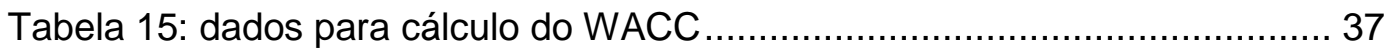

Tabela 16: Fluxo de caixa livre projetado .................................................... 38

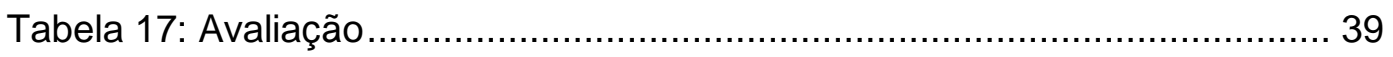




\section{O Tema e o problema de estudo}

\subsection{Introdução ao tema e ao problema de estudo}

A antiga Companhia Vale do Rio Doce foi criada em 1942 na cidade de Itabira, Minas Gerais, durante o governo do Presidente Getúlio Vargas. Por ser uma empresa mista, quem detinha o controle acionário era o governo federal.

Em 1997, durante o governo de Fernando Henrique Cardoso, a Vale passou pelo processo de privatização, gerando para o governo uma receita de $\mathrm{R} \$ 3,3$ bilhões, quantia superior a seu valor de mercado, segundo o livro Vale Nossa História. A partir da privatização, o valor da empresa cresceu significativamente, por conta não só de fatores econômicos como também das especulações no mercado financeiro.

A mudança societária da empresa não só gerou inúmeros empregos como permitiu que os objetivos iniciais de expansão e exploração de minérios e outras riquezas, se tornassem reais. A Vale chegou a se tornar a segunda mineradora mais importante no mundo e atualmente ocupa o terceiro lugar.

Outra mudança significativa foi à ampliação dos segmentos de atuação da companhia, passando a investir em Logística, Siderurgia e Energia além da Mineração, aumentando o número de funcionários em mais de 500\%.

De acordo com o Boston Consulting Group, a Vale foi julgada como uma das 25 maiores geradoras de valor sustentável aos acionistas no mundo, devido ao seu desempenho nos últimos 10 anos.

Em termos de Governança Corporativa, a empresa possui uma Diretoria Executiva formada pelo Diretor-Presidente (CEO) Murilo Ferreira e mais sete diretores executivos. Adicionalmente, há um conselho administrativo que é o responsável pela análise dos planos e projetos propostos pela Diretoria Executiva. 
Atualmente a Vale tem a classificação de "grau investimento", com rating BBB+ pela Standard \& Poor's, Baa2 pela Moody, BBB+ pela Fitch e BBB (high) pela Dominion Bond Rating Service.

Segundo Martins (2001), "ao avaliar uma empresa, objetivamos alcançar o valor justo de mercado, ou seja, aquele que representa de modo equilibrado, a potencialidade econômica de determinada companhia. Entretanto, o preço do negócio somente será definido com base na interação entre as expectativas dos compradores e vendedores. Não existe um valor correto para um negócio. Pelo contrário, ele é determinado para um propósito específico, considerando as perspectivas dos interessados".

Através de uma avaliação de valor (valuation), esse estudo se propõe a estimar o valor da empresa no ano de 2014 e a levantar o preço alvo das ações da companhia para o ano de 2015, comparando os valores encontrados e podendo avaliar a atratividade desses papeis.

Essa avaliação será feita a partir do preço das ações da VALE em 2014 e com base nas projeções realizadas para o crescimento da empresa e para o cenário no qual a empresa atua no período de 2015 a 2022.

Para análise da empresa será utilizado o método de Fluxo de Caixa Descontado, projetando o fluxo de caixa para os anos de 2019, 2020, 2021 e 2022 mesmo prazo das informações extraídas da plataforma Bloomberg. Os dados dos anos 2015 e 2018 não foram projetados, pois além de possuir acesso a essas informações, as projeções do mercado em curto prazo normalmente acompanham o real cenário da empresa. Dados como o beta do mercado e da empresa, a taxa de crescimento, de desconto e de perpetuidade serão calculados como forma de trazer os valores projetados à data de dezembro de 2014.

Com base nessas análises será encontrado o valor da empresa e assim o preço alvo de suas ações verificando as diferenças entre a projeção e o valor real e analisando, ao olhar do investidor, se é vantajoso ou não investir nessa empresa. 
As ações da companhia são negociadas na BM\&Fbovespa (Bolsa de Valores de São Paulo) e nas principais bolsas do mundo, como a NYSE, Euronext Paris, LATIBEX e The Stock Exchange of Hong Kong Limited, com a sigla de VALE3 e VALE5. No dia 25/06/2015 o fechamento da VALE5 foi de $\mathrm{R} \$ 16,50$ e a VALE3 a $\mathrm{R} \$ 19,32$, conforme a Figura 1.

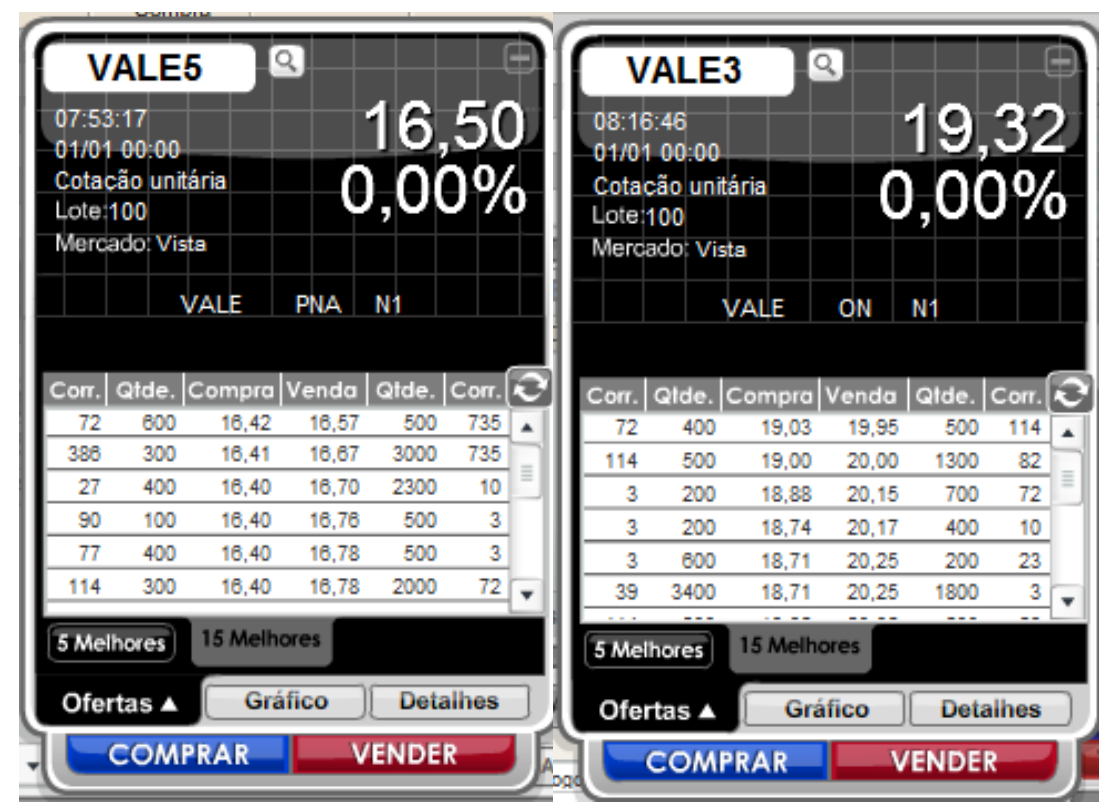

Fonte: Home Broker da Ágora CTVM

Figura 1: Valor das ações da Vale em 25/06/2015

Dessa forma, ao realizar esse estudo será possível, a partir dos valores encontrados, responder a seguinte pergunta: o preço negociado dos ativos da mineradora é justo?

\subsection{Objetivo do estudo}

Esse trabalho tem como objetivo final verificar se o valor de mercado da empresa é coerente com o valor justo das ações ordinárias, e o valor de mercado da empresa através do método de fluxo de caixa descontado. 


\subsection{Objetivos intermediários ao estudo}

Para atender o objetivo final do trabalho, foram levados em consideração alguns outros objetivos intermediários necessários para o cálculo do valor da empresa e suas ações. São eles:

- Analisar o mercado de minério, área de atuação principal da empresa;

- Verificar o Beta do setor e de mercado para achar o da empresa;

- Calcular a taxa de crescimento recente da empresa, a projetando para os anos seguintes;

- Analisar o preço dos insumos nos últimos anos e seu impacto na receita e custos da empresa;

- Utilizar o método de Fluxo de Caixa Descontado para avaliar a empresa e achar o valor de mercado para suas ações, dividindo o primeiro pelo número de ações ordinárias em circulação.

\subsection{Delimitação e foco do estudo}

O estudo busca avaliar e analisar os resultados financeiros da Vale S.A., levando em consideração As informações contábeis auditadas em dezembro de 2014, onde informam o histórico financeiro da empresa dos últimos 5 anos, além de informações com o câmbio, risco-país e beta de mercado deste período.

Outra delimitação do estudo é a utilização do impacto apenas do minério de ferro nas análises sobre a empresa já que este é responsável por mais da metade da receita da mineradora e oscilações no valor deste afetam diretamente o preço dos ativos da Vale.

As projeções do fluxo de caixa futuros para estimar o valor de mercado foram realizadas tomando como base as taxas de crescimento e endividamento 
extraídas do Bloomberg para os anos de 2015 a 2018 e projetadas por mais quatro anos, ou seja, considerando um horizonte total de 8 anos.

\subsection{Justificativa e relevância do estudo}

Este estudo é relevante para analistas do mercado financeiro e possíveis investidores, que buscam informações para tomadas de decisões sobre investimentos. Empresas concorrentes do mesmo setor podem utilizar as informações aqui contidas para análise do mercado, verificar as vantagens competitivas que possuem analisar diretamente o segmento de minério de ferro e obter informações sobre a Vale.

Outro fator importante deste estudo é servir como base para trabalhos futuros, como por exemplo, uma eventual comparação com outras empresas do setor de mineração. Do resultado encontrado nesta análise será possível verificar se existe diferença entre o preço alvo das ações e o valor real. Assim, será possível realizar um novo estudo que explique quais os possíveis fatores não econômicos que estariam causando as divergências entre os valores encontrados. 


\section{Revisão de literatura e referencial teórico}

\subsection{O valor da empresa}

A avaliação de empresas é uma prática bem antiga no campo das finanças e, segundo Copeland, Koller e Murrin (2002), está baseada na abordagem de avaliação desenvolvida pelos professores Merton Miller e Franco Modigliani, ambos ganhadores do Prêmio Nobel, em seu artigo de 1961 publicado no Journal of Business e intitulado "Dividend Policy, Growth and the Valuation of Shares".

Existem vários modelos e métodos de avaliação de empresas que podem ser utilizados em conjunto ou separadamente, sendo que, em sua maioria, nenhum modelo fornece um valor preciso e único para uma empresa, mas sim uma estimativa por considerar premissas, hipóteses e tendências, muitas vezes, subjetivas (Damodaran, 2002).

Na tentativa de avaliar uma empresa é necessário levar em consideração dados passados para realizar projeções futuras, notadamente a partir de consultas às demonstrações contábeis. Além disso, há necessidade de apurar dados que demonstrem a atual realidade de uma organização, e o cenário econômico e político em que está inserida.

O processo de avaliação de empresas é muito utilizado, pois existe a necessidade de precificar o empreendimento, de modo que investidores que possuem interesse em uma determinada empresa possam decidir se desejam aplicar na organização. Internamente, esse processo também é importante já que auxilia na tomada de decisões pelos gestores da empresa.

A avaliação de uma empresa é vista, segundo P. Samanez (2007), como um estudo subjetivo, pois são realizados de acordo com premissas e hipóteses criadas por quem realiza a análise. Apesar disso, existem diversos métodos de 
realizar o valuation, termo em inglês para a expressão Avaliação de Empresas, sendo que alguns desses métodos se destacam no mercado.

\subsubsection{Modelo de fluxo de caixa descontado (FCD)}

De acordo com Copeland, Koller e Murrin (2002), “... o valor de uma empresa é movido por sua capacidade de geração de fluxo de caixa no longo prazo". A partir dessa abordagem, uma das maneiras mais utilizadas de se calcular o valor de uma empresa é através do Fluxo da Caixa Descontado (FCD).

Nesse método, para calcular o valor dos ativos os fluxos de caixa da empresa são calculados para os próximos anos e trazidos a valor presente através de uma taxa de desconto adequada ao nível de risco deste fluxo de caixa. O Fluxo de Caixa de um ativo pode ser obtido através do Balanço Patrimonial e do Demonstrativo de Resultado e Exercício (DRE).

Como citado anteriormente, o modelo do fluxo de caixa descontado é a principal metodologia utilizada para se avaliar empresas, e é o método que melhor calcula a capacidade de geração de riqueza de um determinado investimento, analisando a eficiência do negócio. A avaliação através do fluxo de caixa procura retratar o potencial econômico dos itens patrimoniais de determinado empreendimento.

O método FCD é utilizado por corretoras e bancos de investimentos, consultorias e empresários quando querem calcular o valor de uma empresa, seja para fins internos, de análise de investimentos ou para fusões e aquisições.

O valor de uma empresa é medido por sua capacidade de criação de valor, ou seja, a capacidade no longo prazo de gerar fluxos de caixa, levando em conta o crescimento da empresa e o retorno sobre o capital investido em relação ao custo do capital da empresa. 
A premissa dessa metodologia baseia-se que o valor do ativo depende do fluxo de caixa futuro produzido pela empresa trazido a valor presente através da taxa de desconto que refere ao risco do mercado, setor e empresa (beta). Ou ainda, conforme Damoradan (2007), o valor presente da firma pode ser calculado através do resultado operacional descontando o imposto e levando em consideração a depreciação, investimentos e variação do capital de giro, descontado pela taxa de custo médio ponderado de capital.

A equação que representa o modelo ou método de fluxo descontado é:

$$
V P L=\sum F C L(t) /(1+W A C C)^{t}
$$

Onde:

$\mathrm{FCL}(\mathrm{t})=$ Fluxo de caixa livre projetado no período $\mathrm{t}$

WACC = Custo médio ponderado de capital

$\mathrm{t}=$ Período

\subsubsection{Fluxo de caixa livre (FCL)}

Segundo Samanez (2007), o Fluxo de Caixa Livre de uma empresa é aquele que, após todos os dispêndios necessários à sua manutenção e crescimento, estão realmente disponíveis para distribuição aos acionistas e demais investidores da organização:

"O fluxo de caixa livre (FCL) mede o poder de geração de renda econômica por parte da empresa, sem considerar os fluxos ligados ao aspecto financeiro. É o fluxo de caixa efetivamente disponível para distribuição aos acionistas e credores, depois da empresa ter feito todos os dispêndios de capital necessários para manter-se operacional, assegurar sua permanência e crescimento". 


\section{- Fluxo de caixa líquido para a firma (FCFF)}

Chamado também como fluxo de caixa dos ativos, o FCFF é uma avaliação da empresa levando em consideração todos os detentores de direito e obrigações da empresa.

O fluxo de caixa líquido para a firma (FCFF) pode ser representado pela seguinte fórmula:

\section{$\operatorname{EBIT}^{*}(1-\mathrm{t})$}

(+) Depreciação

= Fluxo de caixa líquido gerado pelas operações

(+-) Variação da necessidade de capital de giro

(-) Despesas de capital líquido (investimentos)

= Fluxo de caixa livre para a firma

Ao projetar o fluxo de caixa livre, é necessário determinar o período para que a empresa atinja um crescimento constante, ou seja, alcance a maturidade. Esse período depende da capacidade da empresa em gerar receita para manter seus investimentos.

Neste período determinado são geradas hipóteses de crescimento a partir de dados históricos e as premissas utilizadas para projetar as vendas, custos e outros, através das taxas de perpetuidade e de crescimento.

\section{- Despesas de capital líquidas (investimentos)}

O termo em inglês Capex, sigla para capital expediture, com tradução despesas de capital ou investimento em bens de capital, é utilizado para calcular o montante utilizado para melhorias e expansão de uma determinada empresa, como gastos com imobilizados. Segundo Costa, Costa, Alvim (2010), gastos de capital são os gastos necessários para gerar fluxo de caixa futuro. 
Os gastos líquidos de capital podem ser obtidos através da análise das demonstrações financeiras de uma empresa utilizando o valor gasto com ativos imobilizados menos os valores decorrentes da venda de ativos imobilizados.

\section{- Variação da necessidade de capital de giro (NCG)}

As empresas necessitam, além de investir em Capex, investir no ativo circulante. Por conta disso, deve-se considerar a variação ao longo do tempo da necessidade de capital de giro na determinação do FCFF.

Segundo Costa, Costa, Alvim (2010), a variação da necessidade de capital de giro é um ajuste necessário para transformar receitas em recebimentos e despesas em pagamentos. Os recebimentos correspondem às receitas com vendas descontadas a variação de duplicatas a receber. Os pagamentos correspondem às compras subtraídas a variação de fornecedores.

\section{- Beta}

Valores como Beta de mercado e Beta de regressão foram retirados de análises financeiras da Ágora Corretora e do site do Damodoran. Para calculo do beta alavancado foi utilizada a fórmula a seguir.

$$
\beta a=\beta 0^{*}\left\{1-T^{*}[D /(C P)\}\right.
$$

Onde:

$\beta a=$ Beta alavancado

$\beta 0=$ Beta desalavancado

$\mathrm{T}=$ Alíquota de imposto (34\%)

$\mathrm{D}=$ Dívida financeira

$\mathrm{CP}=$ Valor de mercado do capital próprio 


\subsubsection{Custo médio ponderado de capital (WACC)}

Segundo Copeland, Koller e Murrin (2010), os principais fatores que influenciam o fluxo de caixa descontado livre de uma empresa são a taxa de crescimento de suas receitas, e o retorno esperado sobre o capital investido, isto é, o custo de capital.

No caso de uma empresa, a taxa de desconto mais utilizada é o WACC (Weighted Average Cost of Capital), o custo médio ponderado de capital. Essa taxa mede a remuneração requerida sobre o capital investido. Essa taxa mede também o custo de oportunidade dos investidores ou credores do negócio.

Segundo Assaf Neto (2004), o custo de capital é estabelecido pelas condições com que a empresa obtém seus recursos financeiros no mercado de capitais, sendo geralmente determinados por uma média dos custos de oportunidade do capital próprio e de terceiros, ponderados pelas respectivas proporções utilizadas de capital líquidas do imposto de renda.

A fórmula representativa do WACC é:

$W A C C=E /(E+D){ }^{*} K e+\left\{[D /(E+D)]{ }^{*} K d{ }^{*}(1-T)\right\}$

Onde:

WACC $=$ custo de capital médio ponderado

$\mathrm{E}=$ Patrimônio líquido

$\mathrm{D}=$ Dívida financeira

$\mathrm{T}=$ Alíquota de imposto

$\mathrm{Ke}=$ Custo de capital próprio

$\mathrm{Kd}=$ Custo de capital de terceiros 


\section{- Custo de capital próprio (Ke)}

O cálculo realizado para encontrar o custo do capital próprio será através do modelo CAPM (Capital Asset Pricing Model). Esse método, segundo Costa, Costa e Alvim (2010), determina a taxa de retorno teórica apropriada de um determinado ativo em relação a uma carteira de mercado, representa a taxa de rentabilidade exigida pelos investidores como compensação pelo risco de mercado a que estão expostos.

A fórmula mostra que o custo de oportunidade do capital tem que ser igual ao retorno da taxa livre de risco da economia, acrescentado o risco sistêmico da empresa (beta) multiplicado pelo prêmio de mercado do risco.

\section{$\mathrm{Ke}=\mathbf{R f}+\boldsymbol{B}^{*}(\mathbf{R m}-\mathbf{R f})$}

Onde:

$R f=$ é o retorno esperado de um ativo livre de risco (ex: título público).

$\mathrm{Rm}=$ Taxa de retorno prevista para a carteira de mercado como um todo, é o prêmio que o investidor pretende ter.

$B=E ́$ o coeficiente de risco que compara a empresa com mercado de ações, seu objetivo é mensurar a volatilidade da empresa.

$(\mathrm{Rm}-\mathrm{Rf})=$ prêmio de risco do mercado

$B^{*}(R m-R f)=$ prêmio de risco do ativo

No Brasil, Segundo Costa, Costa e Alvim (2010), a taxa Selic (Sistema Especial de Liquidação e Custódia) é usada por acadêmicos e analistas financeiros como taxa livre de risco no modelo CAPM, para compor o custo de capital próprio. Porém, nos países em desenvolvimento os títulos públicos não têm grau de maturidade para serem considerados totalmente livres de risco. Assim, há necessidade de se acrescentar ao custo de capital próprio uma parcela que represente o risco específico do país. 
O Risco-País é uma medida que visa classificar o risco geral de um país em função de seu nível estabilidade econômica.

Ao calcular o valor de uma empresa, é comum utilizar como taxa livre de risco a taxa de retorno média de título de dívida emitido pelo governo dos Estados Unidos, devidamente ajustada por um índice que represente o risco pais. Neste estudo será utilizado na adequação da taxa livre de risco o índice $\mathrm{EMBI}+$ (Emerging Markets Bond Index Plus), que é a medida mais utilizada pelo mercado para expressar o nível de risco de um país e é calculado pelo banco de investimentos americano J. P. Morgan.

\section{- Custo do capital de terceiros (Kd)}

O custo de capital de terceiros está relacionado com o risco à empresa não conseguir honrar os seus compromissos e suas dívidas. Quanto maior o Kd, maior é o risco do empreendimento e, consequentemente maior será o retorno esperado pelo investidor ao investir em uma determinada empresa.

No cálculo do custo oportunidade do capital de terceiros se leva em conta o custo da dívida de longo prazo da empresa, dela se descontando o benefício fiscal, conforme indicado na fórmula abaixo.

$$
\mathrm{Kd}=(1-\mathrm{T}){ }^{*} \mathrm{Rd}
$$

Onde:

$\mathrm{Rd}=$ custo da dívida a longo prazo

$\mathrm{T}=$ taxa de imposto de renda 


\subsection{Outros métodos de avaliação}

Segundo Almeida (2010, p.72), "na tentativa de calcular o valor justo de uma empresa, diversos autores apresentaram modelos de avaliação, não obstante, devido a sua complexidade e subjetividade a valorização de empresas ainda é tema de inúmeras discussões acadêmicas e profissionais".

Assim, podemos observar que adicionalmente ao método do fluxo de caixa descontado existem diversos outros modelos de avaliação financeira de uma empresa, como por exemplo, o Modelo de Fluxo de Dividendos Descontados e o Método de Múltiplos de Mercado.

Porém, para efeito de atingir os objetivos propostos para este estudo, será utilizado somente o método de fluxo de caixa descontado. 


\section{Métodos e procedimentos de coleta e de análise de dados do estudo}

\subsection{Etapa de coleta de dados}

O levantamento de dados necessário à realização desse estudo foi feito através de dados secundários. Foram utilizadas fontes diversas tais como livros, documentos contábeis, artigos e ferramentas informatizadas tais como Bloomberg e Home Broker da Ágora CTVM.

Pela necessidade de utilizar informações auditadas e pela obrigatoriedade da Vale fornecer aos seus acionistas e ao mercado informações da saúde financeira da empresa, assim como seus objetivos para os próximos anos, não houve necessidade de recorrer a fontes primárias como profissionais e gestores da empresa analisada.

Apesar dos dados disponíveis nas fontes secundárias conterem todas as informações necessárias para realização desse trabalho, facilitou significativamente o processo de identificação e recuperação das informações necessárias à realização do presente estudo o auxílio de analistas financeiros da Vale e da Ágora CTVM obtido pela autora.

\subsection{Fontes de informações selecionadas para coleta de dados}

As informações contidas no Capítulo 1, "O tema e o problema de estudo" e no Capítulo 4, "A empresa", foram extraídas de livros acadêmicos, do livro em homenagem aos 70 anos da mineradora e de notícias de revistas e jornais. Para o Capítulo 2, "Revisão de literatura e referencial teórico", os dados foram coletados através de livros acadêmicos e artigos referentes ao tópico abordado. 
As informações e dados obtidos para o Capítulo 3, "Métodos e procedimentos de coleta e de análise de dados de estudo" e do Capítulo 5, "Apresentação e análise dos resultados", foram obtidos a partir de ferramentas como Bloomberg e Home Broker da empresa Ágora CTVM, bem como através dos relatórios anuais e demonstrações financeiras divulgados pela Vale em seu sítio, na sessão Relação com os Investidores.

\subsection{Procedimento e instrumentos de coleta de dados}

Para a coleta de dados foram utilizados os demonstrativos financeiros divulgados no sítio da Vale, exportados para o Excel para que fosse possível realizar o tratamento de dados e análises necessárias. Os dados extraídos do Bloomberg foram exportados para a mesma ferramenta.

\subsection{Formas de tratamento e análise dos dados coletados}

Os dados coletados nos relatórios da companhia e do Bloomberg foram exportados para análise em planilhas do Excel, utilizando as facilidades dessa ferramenta para realizar as projeções necessárias.

\subsection{Limitações do método}

Conforme citado por Eco (2014), uma limitação do método de pesquisa a partir de dados secundários está relacionada à confiabilidade e correção desses dados. Para minimizar essa limitação, este estudo buscou coletar dados nas fontes de informações com maior credibilidade, evitando distorções de valores ou qualquer viés nas análises. Um exemplo disso foi a utilização de demonstrativos financeiros padronizadas fornecidas pela companhia e disponibilizada pela Comissão de Valores Mobiliários (CVM), Bloomberg e sítio 
da empresa Ágora CTVM. Outra delimitação é a utilização do método de Fluxo de Caixa Descontado para achar o valor da empresa. 


\section{A empresa}

No meio das notícias sobre a Segunda Guerra Mundial no ano de 1942 , alguns jornais brasileiros guardaram um espaço para divulgação da nova Companhia Brasileira de Mineração e Siderurgia, a antiga Companhia Vale do Rio Doce, empresa de sociedade anônima, de economia mista com um capital de aproximadamente 200 mil contos de réis, moeda brasileira da época. A diretoria da Companhia seria composta por um diretor-presidente, de livre escolha pelo presidente da República Getúlio Vargas, e por quatro diretores escolhidos pela assembleia geral.

De acordo com o livro "Vale, Nossa História", lançado em 2012 e disponível no sítio da empresa, após 70 anos de atuação e crescimento no mercado, a empresa obteve um lucro líquido de 22,9 bilhões de dólares em 2011, ocupando a posição de segunda maior mineradora mundial, uma posição a cima da que ocupa atualmente.

Com base nesse mesmo livro, até 2012, a empresa possuía 139 mil empregados atuando em 37 países. A empresa ampliou a produção de ferro, cobre, níquel, carvão, fertilizantes e diversos outros produtos, ultrapassando o objetivo inicial que era produzir 1,5 milhão de toneladas de minério de ferro, chegando a produzir mais de 5 bilhões de toneladas de minério de ferro em 2012.

Com a crise econômica brasileira dos anos 1980, as empresas Estatais foram profundamente afetadas. Assim, com o objetivo de gerar caixa e diminuir o déficit, em 1997 a antiga Vale do Rio Doce (CVRD) foi privatizada, tendo o consórcio liderado pela Companhia Siderúrgica Nacional, adquirindo o seu controle acionário por $\mathrm{R} \$ 3.338 .178 .240,00$. Isso representou um ágio de $19,9 \%$ em relação ao preço inicial fixado. As ações foram vendidas por $R \$ 32,00$ cada, enquanto o preço original era de $R \$ 26,67$ e foi permitido que os brasileiros comprassem ações utilizando seu FGTS. 
Neste mesmo ano entrou em vigor a Lei Kandir, que isentava a companhia dos impostos referentes à exportação de produtos não industrializados como o minério de ferro, o que reduziu os custos da empresa.

De acordo com dados do jornal Gazeta Online, após 15 anos da privatização além de um aumento superior a $500 \%$ no número de funcionários, a empresa passou a produzir mais de 300 milhões de toneladas de minério de ferro, obtendo um lucro líquido de $R \$ 37,8$ bilhões no ano de 2011 contra 1,3 bilhões em 2007.

Outra mudança significativa foi a alteração nos segmentos de atuação da companhia, passando a investir em Logística, Siderurgia e Energia além da Mineração conforme ilustra a Figura 3. A Vale também aumentou o valor investido para aproximadamente US\$ 17,9 bilhões em 2011 e desde a privatização até o esse ano as ações ordinárias tiveram um rendimento superior a $4.290 \%$.

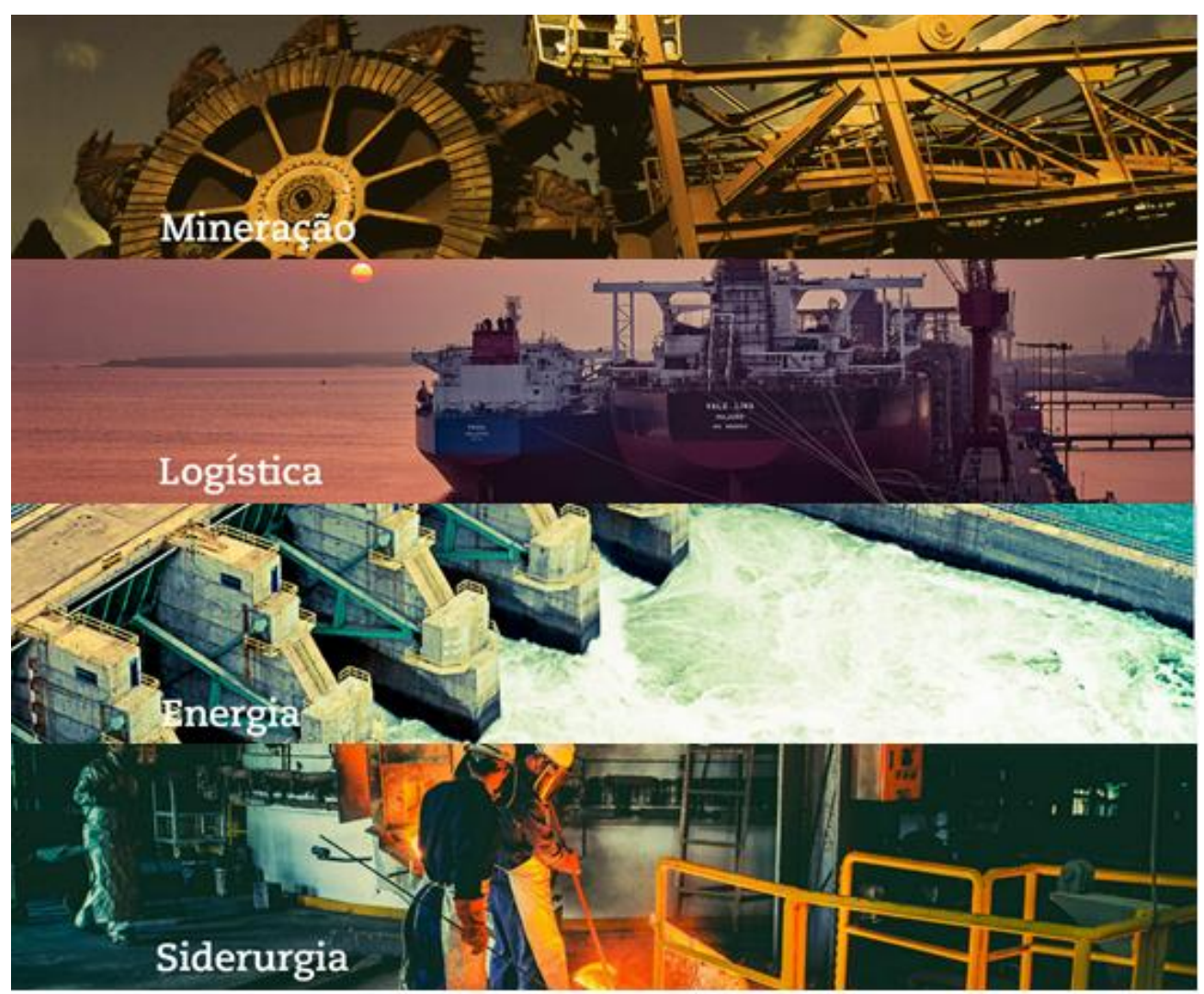

Fonte: Sítio da empresa Vale

Figura 2: Áreas de atuação da empresa Vale. 
Estando presente em 37 países, a empresa sofreu uma acentuada desvalorização dos seus ativos em comparação aos anos anteriores devido a oscilação negativa do minério de ferro e pela falta de confiabilidade no mercado brasileiro, fazendo com que os investidores estrangeiros deixassem de procurar essas ações ou investimentos no país, de acordo com analistas financeiros.

Em 24 de outubro de 2006 a Vale anunciou a incorporação da canadense Inco, a maior mineradora de níquel do mundo. Em 2008 seu valor de mercado foi estimado em 196 bilhões de dólares pela consultoria Economática, perdendo no Brasil apenas para a Petrobras (287 bilhões) e se tornando a $12^{\mathrm{a}}$ maior empresa do mundo.

Em 2014, com o histórico de excesso de fornecimento do minério de ferro o preço da tonelada se manteve em declínio tendo por consequência a desvalorização das ações da companhia. Com esse cenário é esperado que os pequenos produtores não consigam se manter no mercado, o que beneficiaria a Vale e outras mineradoras.

Com a queda do barril de petróleo em 2015, a Vale conseguiu superar seus concorrentes oferecendo o menor custo pelo seu produto. Essa vantagem competitiva foi possível, pois foi possível baratear o custo do transporte que antes, do Brasil para China, era gasto em média US\$23,00 por tonelada, enquanto o custo mais baixo de transporte era oferecido pela Austrália, com um gasto de US $\$ 9,00$ a tonelada.

Atualmente, o custo de transporte chegou a patamares menores que US\$ 10,00 a tonelada, e ao somar com outros custos de produção tornou possível para a Vale transportar minério de ferro mais barato que seus concorrentes. 


\subsection{Missão, visão e valores}

A missão da Vale é transformar os recursos naturais em prosperidade e desenvolvimento sustentáveis.

A visão é ser a empresa de recursos naturais global número um em criação de valor de longo prazo, com excelência, paixão pelas pessoas e pelo planeta. É essa visão que faz com que a Vale continue investindo e buscando o crescimento mesmo depois de ter se consolidado do mercado.

Seus principais valores, conforme sítio da mineradora são:

$>$ A vida em primeiro lugar;

> Valorizar quem faz a nossa empresa;

$>$ Cuidar do nosso planeta;

$>$ Agir de forma correta;

$>$ Crescer e evoluir juntos;

$>$ Fazer acontecer.

\subsection{Composição acionária}

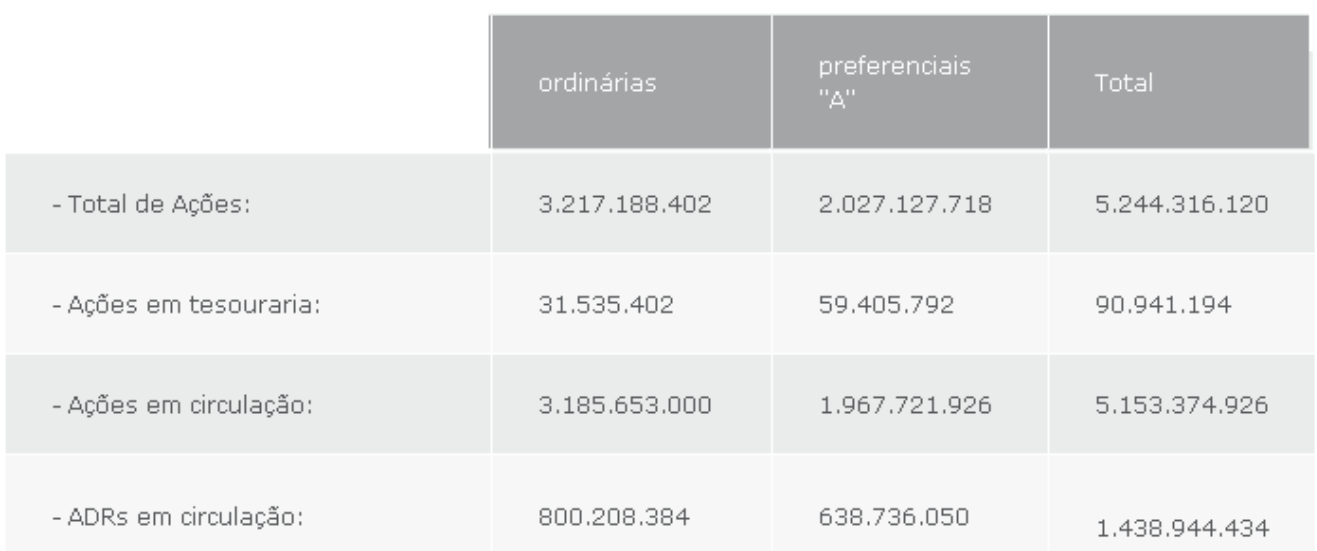

Fonte: Relatórios da Vale

Tabela 1: Composição acionária da empresa Vale em 30/12/2014 
A Vale possui duas ações negociadas em bolsa, as ações ordinárias VALE3, que são as que possuem direito a voto e as ações preferencias VALE5. Os portadores desta possuem prioridade no recebimento de proventos pagos pela empresa, ou seja, o recebimento de dividendos e juros sobre capital próprio.

\subsection{Análise do mercado}

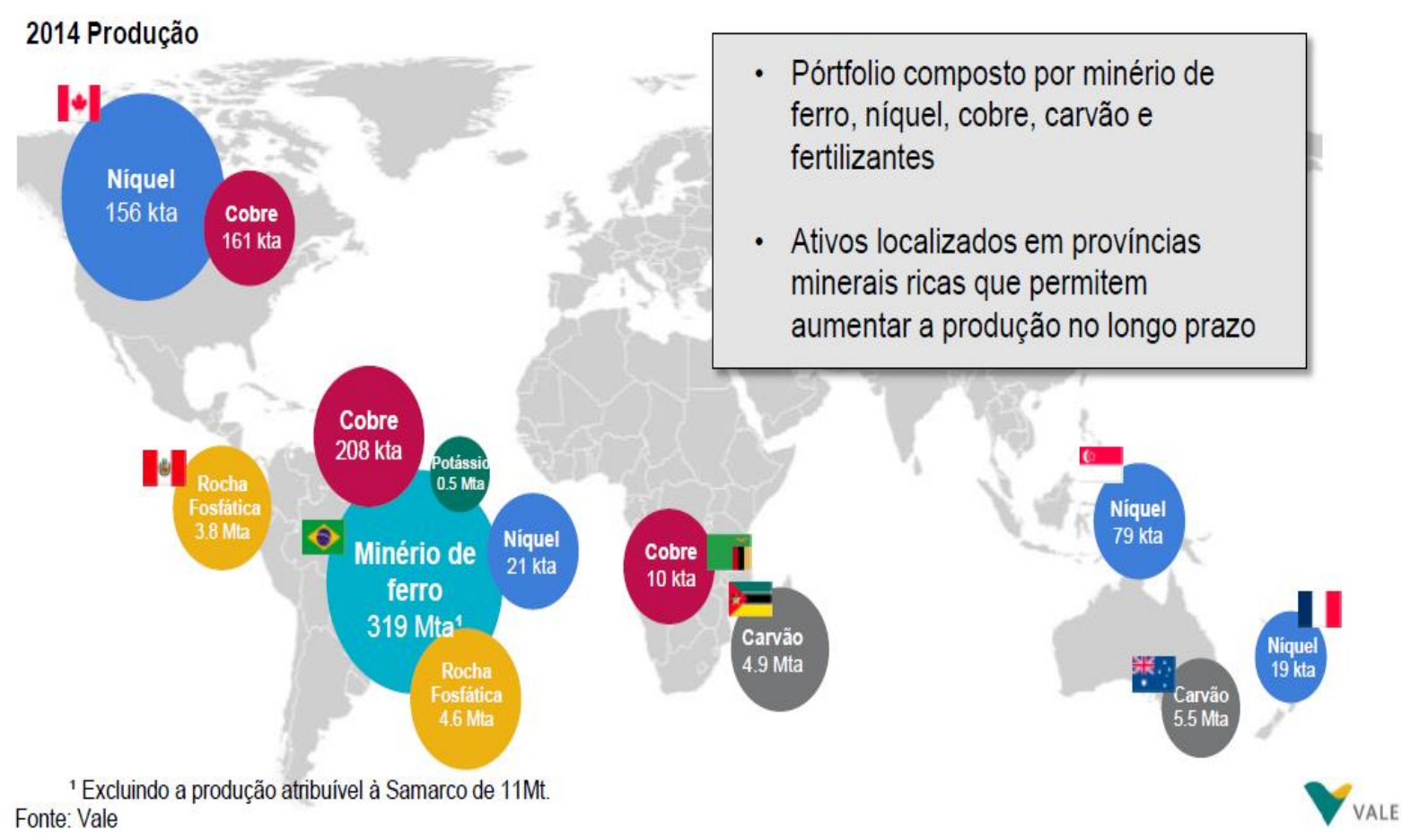

Fonte: Relatórios da Vale

Figura 3: Produção da Vale em 2014

Para obter sucesso no setor de mineração exige-se uma gestão efetiva dos custos de produção, reflexo de um dos valores mais baixos para o minério de ferro, é isso que tem sido observado pelas principais mineradoras. Estima-se que os custos de mineração, que aumentaram 32\% entre 2003 e 2010, poderão se elevar até $40 \%$ ou mais nos próximos dez anos (Accenture,2013b; MacNamara 2011).

Em 2014, 25\% do custo total de produção de minério de ferro estava atrelada a gastos com energia e é esperado que a curto prazo esses custos aumentem. Para efeitos de comparação, esse montante também é significativo em outras regiões, tais como Canadá (19\%), África do Sul (23\%) e Austrália 
(14\%) (Accenture, 2013b) e esse custo da energia tende a aumentar nos próximos anos.

Os custos operacionais também tendem a aumentar devido à dificuldade em encontrar minas de classe mundial e pela queda na qualidade das reservas minerais. Outro fato que contribuí com o esse possível aumento é o fato dos governos tenderem a aumentar os impostos de exportação sobre lucros e royalties de mineração.

As mineradoras enfrentam um mercado com reservas mais escassas, dificuldade em encontrar mão de obra e obter equipamentos de qualidade. Por isso, as grandes empresas que atuam nesse setor, possuem vantagens competitivas em frente às menores, por estarem consolidadas nesse mercado e com planejamentos para enfrentar possíveis alterações ou crises.

Apesar da alta volatilidade, a demanda por commodities de mineração tende a aumentar no curto prazo, tendo em vista o desenvolvimento econômico dos países em crescimento, como a China. Estima-se que existe um movimento migratório das famílias que residem em áreas rurais para áreas urbanas, o que implicam em elevação dos gastos em infraestrutura, transporte, energia e bens duráveis gerando um consumo sustentável de bens de consumo, aumentando a demanda pelo minério de ferro.

Em 2014 a produção do minério de ferro ultrapassou um bilhão de toneladas e a previsão de importação para 2016 é superior a 900 milhões de toneladas apenas para a China.

\subsection{Evolução do preço}

Conforme o histórico ilustrado na Figura 4, o preço do minério de ferro desvalorizou, porém analistas da Vale acreditam que o preço volte a patamares anteriores já que pequenos produtores chineses não conseguirão manter a rentabilidade e encerrariam a produção. Com isso, a China dependerá mais do minério de ferro importado, aumentando a demanda. 


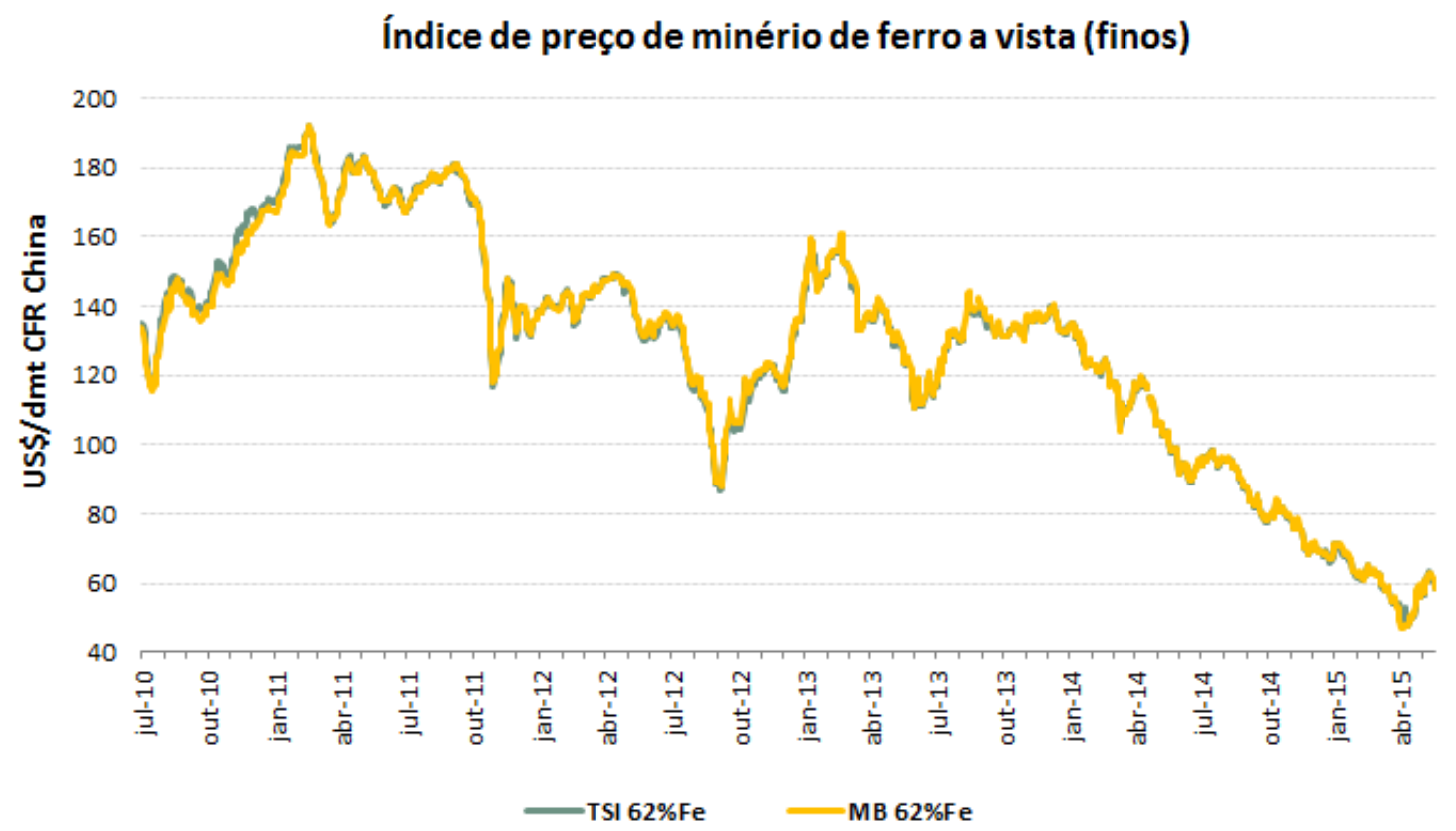

Fonte: Relatórios da Vale

Figura 4: Histórico do preço do minério de ferro 


\section{Apresentação e análise dos resultados}

\subsection{Premissas utilizadas}

Ao desenvolver as premissas para a análise da Vale, foram utilizados cotação das ações, câmbio do dólar e histórico dos dados contábeis consolidados no dia 30 de dezembro de 2014.

\section{- Segmento}

Responsável por mais da metade do faturamento da Vale, com um percentual de aproximadamente $56 \%$ sobre a receita gerada, as estimativas sobre o crescimento de produção e venda do minério do ferro foram às únicas levadas em consideração ao realizar as projeções dos números e indicadores da empresa.

\section{- Taxa de perpetuidade}

O aumento nos investimentos realizados pela Vale resultou no crescimento do número das instalações e por consequência o aumento do volume da capacidade de produção, melhorando o desempenho financeiro da empresa. Assim, para calcular a taxa de perpetuidade será levado em consideração o crescimento da empresa, dividindo o fluxo de caixa descontado pela diferença da taxa de desconto e a taxa de crescimento. 


\section{- Taxa de crescimento}

Segundo Damodaram (2004), pode-se assumir a existência de relação entre a taxa de crescimento da empresa no passado e a taxa de crescimento projetada para o futuro. Assim, nesse estudo, a taxa de crescimento foi calculada utilizando como base a média das taxas de crescimento da Vale nos últimos 5 anos.

\subsection{Projeções}

\section{- Volume de produção e de vendas}

Para a projeção da receita bruta, foi necessário verificar o volume produzido e vendido de minério de ferro nos últimos cinco anos e calcular o valor como se o minério de ferro fosse à única fonte de receita da empresa.

\begin{tabular}{|l|c|c|c|c|c|c|c|c|c|c|}
\hline R\$̦ milhões & $\mathbf{2 0 1 0}$ & $\%$ & $\mathbf{2 0 1 1}$ & $\boldsymbol{\%}$ & $\mathbf{2 0 1 2}$ & $\mathbf{\%}$ & $\mathbf{2 0 1 3}$ & $\boldsymbol{\%}$ & $\mathbf{2 0 1 4}$ & $\%$ \\
\hline Minério de ferro & 45.419 & 53,2 & 58.989 & 58 & 53.492 & 56 & 61.198 & 59,4 & 45.661 & 50,8 \\
\hline Total & $\mathbf{8 5 . 3 4 5}$ & 100 & $\mathbf{1 0 1 . 0 7 5}$ & 100 & $\mathbf{9 5 . 5 7 7}$ & 100 & $\mathbf{1 0 3 . 0 2 7}$ & 100 & $\mathbf{8 9 . 9 1 1}$ & 100 \\
\hline
\end{tabular}

Fonte: Tabela desenvolvida pelo pesquisador com base nos relatórios da Vale.

Tabela 2: Receita operacional bruta por área do minério de ferro

De acordo com o relatório Capex 2015, disponível no sítio da empresa, a produção estimada de minério de ferro é de 340 mil toneladas, com crescimento de $6,5 \%$ em relação à produção de 2014. É esse crescimento que será utilizado até o ano de 2022, visto que as projeções do mercado e da Vale são de aumento contínuo da produção de minério para atender a demanda para os próximos anos. 
Nos últimos anos, mesmo com a queda do preço e da demanda do minério de ferro, o volume de produção continuou subindo, o que gerou a premissa que este cenário não sofrerá alterações nos próximos anos.

\begin{tabular}{|l|c|c|c|c|c|c|}
\hline Mil toneladas & $\mathbf{2 0 1 0}$ & $\mathbf{2 0 1 1}$ & $\mathbf{2 0 1 2}$ & $\mathbf{2 0 1 3}$ & $\mathbf{2 0 1 4}$ & Média \\
\hline Volume produzido & 297.000 & 322.600 & 309.000 & 299.800 & 319.200 & $\mathbf{3 0 9 . 5 2 0}$ \\
\hline Volume vendido & 247.007 & 257.278 & 258.061 & 258.061 & 255.877 & $\mathbf{2 5 3 . 8 5 2}$ \\
\hline Total & $83,2 \%$ & $79,8 \%$ & $83,5 \%$ & $83,7 \%$ & $80,2 \%$ & $\mathbf{8 2 , 1 \%}$ \\
\hline
\end{tabular}

Fonte: Tabela desenvolvida pelo pesquisador com base nos relatórios da Vale.

Tabela 3: Volume histórico do minério de ferro

\section{- Volume de vendas}

O volume de vendas foi calculado utilizando a média da relação entre a venda e a produção, conforme a Tabela 4. Assim para o ano de 2015, por exemplo, é necessário calcular $82,1 \%$ das 340 mil toneladas que é o valor estimado de venda, e a partir de 2016 utiliza o crescimento de 6,5\%.

\section{- Preço do minério de ferro}

A partir de dados extraídos do Bloomberg, foi possível obter a previsão do preço de minério de ferro para os anos de 2015 a 2018. Para os demais anos assumiu-se a premissa que o preço se manteria. Por conta disso, se assumiu no primeiro período um crescimento de $6,5 \%$ do volume produzido e posteriormente a média móvel.

\begin{tabular}{|l|c|c|c|c|}
\hline Cotação do Dólar R\$3,15 & $\mathbf{2 0 1 5}$ & $\mathbf{2 0 1 6}$ & $\mathbf{2 0 1 7}$ & $\mathbf{2 0 1 8}$ \\
\hline R\$ & $\mathrm{R} \$ 196,88$ & $\mathrm{R} \$ 204,75$ & $\mathrm{R} \$ 223,65$ & $\mathrm{R} \$ 246,65$ \\
\hline US & $\$ 62,50$ & $\$ 65,00$ & $\$ 71,00$ & $\$ 78,30$ \\
\hline
\end{tabular}

Fonte: Tabela desenvolvida pelo pesquisador de acordo com o Bloomberg

Tabela 4: Projeção do preço do minério de ferro 


\section{- Receita bruta}

Para o cálculo da receita bruta do minério de ferro foi utilizado a média do impacto do minério de ferro na receita da empresa nos últimos 4 anos, já que este segmento representou em média 55,5\%. Foi utilizado para o ano de 2015, o dado extraído da Bloomberg que apontava uma produção de 340 mil toneladas e calculado o percentual de vendas em cima do produzido. Para os demais anos foi calculada de acordo com a taxa de crescimento.

\section{- Deduções da receita bruta}

As deduções da receita bruta levaram em conta para o ano de 2015, 0 crescimento da receita bruta de 2014 para 2015, que foi cerca de 10\%, e assim sucessivamente até 2018. Para os anos seguintes foram projetados com um crescimento de $6,5 \%$ como dito anteriormente.

\section{- Projeção do EBIT}

De acordo com a receita líquida e a margem EBIT histórica dos últimos anos, foi criada a premissa que a margem permaneceria a mesma nos anos desse estudo.

\begin{tabular}{|l|c|c|c|c|c|}
\hline & $\mathbf{2 0 1 0}$ & $\mathbf{2 0 1 1}$ & $\mathbf{2 0 1 2}$ & $\mathbf{2 0 1 3}$ & $\mathbf{2 0 1 4}$ \\
\hline (=) Receita Líquida & 83.225 & 98.743 & 91.269 & 101.494 & 88.276 \\
\hline (=) EBIT & 40.490 & 46.360 & 28.293 & 38.240 & 19.724 \\
\hline (\%) Margem EBIT & $\mathbf{4 8 , 7 \%}$ & $\mathbf{4 7 , 0} \%$ & $\mathbf{3 1 , 0} \%$ & $\mathbf{3 7 , 7 \%}$ & $\mathbf{2 2 , 3 \%}$ \\
\hline
\end{tabular}

Fonte: Tabela desenvolvida pelo pesquisador.

\section{Tabela 5: EBIT e margem EBIT}




\begin{tabular}{|l|c|c|c|c|c|c|c|c|}
\hline & 2015 & 2016 & 2017 & 2018 & $\mathbf{2 0 1 9}$ & $\mathbf{2 0 2 0}$ & $\mathbf{2 0 2 1}$ & $\mathbf{2 0 2 2}$ \\
\hline (=) Receita Líquida & 96.528 & 106.915 & 124.375 & 146.078 & 133.240 & 136.318 & 138.200 & 138.459 \\
\hline (=) EBIT & 33.295 & 36.877 & 42.900 & 50.386 & 45.958 & 47.019 & 47.668 & 47.758 \\
\hline (\%) Margem EBIT & $37,32 \%$ & $37,32 \%$ & $37,32 \%$ & $37,32 \%$ & $37,32 \%$ & $37,32 \%$ & $37,32 \%$ & $37,32 \%$ \\
\hline
\end{tabular}

Fonte: Tabela desenvolvida pelo pesquisador.

\section{Tabela 6: Projeções EBIT e margem EBIT}

Para cálculo da Margem Ebit foram utilizados os últimos 5 anos conforme a Tabela 6 e encontrado a média. O EBIT, para fins de projeções, crescerá de acordo com a receita líquida.

\section{- Projeção dos impostos}

A alíquota de impostos foi projetada como sendo a média entre os anos 2010 e $2014,15,93 \%$, sem grandes oscilações.

\section{- Projeção dos investimentos}

A partir do Capex orçado histórico dos últimos 5 anos divulgado no site da Vale, e do Capex executado de cada ano calculado do Balanço Patrimonial, foi calculado a relação entre o Capex executado e o orçado, assim foi possível projetar a média dos demais anos.

De acordo com relatórios extraídos do Bloomberg, o orçamento para Capex do ano de 2015 ficou no valor de $\mathrm{R} \$ 27.006$ milhões, e através da relação com o ano anterior foi projetado o Capex executado para o ano de 2015.

Observando a Tabela 8, é possível notar que o Capex, executado e o Capex orçado diminuíram ao longo dos anos, entretanto, de acordo com anúncios feitos pela Vale ocorrerá aumento dos investimentos nos próximos anos. Assim será mantido o valor projetado do Capex de 2015 para os anos seguintes. 


\begin{tabular}{|c|c|c|c|c|c|c|c|}
\hline & 2010 & 2011 & 2012 & 2013 & 2014 & Média & 2015 \\
\hline Ativo permanente final & 148.361 & 171.644 & 192.277 & 207.404 & 255.621 & & \\
\hline (-)Ativo permanente inicial & & 148.361 & 171.644 & 192.277 & 207.404 & & \\
\hline (+) Depreciação & 5.741 & 6.638 & 8.397 & 8.953 & 10.108 & & \\
\hline$(=)$ CAPEX executado & & 29.921 & 29.030 & 24.080 & 28.325 & & 15.236 \\
\hline (=) CAPEX orçado & & 63.749 & 56.843 & 43.296 & 39.312 & & 27.006 \\
\hline Executado/orçado (\%) & & $46,94 \%$ & $51,07 \%$ & $55,62 \%$ & $72,05 \%$ & $56,42 \%$ & $56,42 \%$ \\
\hline Depreciação & 5.741 & 6.638 & 8.397 & 8.953 & 10.108 & 8.524 & 8.524 \\
\hline
\end{tabular}

Fonte: Tabela desenvolvida pelo pesquisador com base nos relatórios da Vale.

Tabela 7: Capex protejado (em milhões)

- Projeção da depreciação

Para a projeção da depreciação, a premissa adotada foi a média móvel dos valores dos últimos 4 anos para o ano de 2015 e após adotou o crescimento de $5,5 \%$.

- Projeção variação da necessidade de capital de giro (NCG)

Segundo Costa, Costa, Alvim (2010), parar projetar a variação da necessidade de capital de giro é necessário estabelecer os prazos médios de pagamento e recebimento. Assim, foi calculada a média histórica dos últimos 4 anos da relação Variação NCG com a receita líquida sendo esta, projetada para os próximos anos.

\subsection{Custo do capital próprio (CAPM)}


- Beta

É de praxe o mercado utilizar uma amostra dos últimos 5 anos para estimar o beta. Assim ao realizar os cálculos foram utilizados os dados históricos de janeiro de 2010 a janeiro de 2014, obtendo o beta de regressão da ação da Vale contra o Ibovespa de $0,91$.

Foi utilizado o mesmo método para as ADRs da Vale contra o S\&P 500, obtendo um beta de 1,25.

\begin{tabular}{|c|c|c|c|c|c|c|}
\hline Industria & $\begin{array}{c}\text { Número } \\
\text { de firmas }\end{array}$ & $\begin{array}{c}\text { Beta } \\
\text { desalavancado } \\
\text { médio }\end{array}$ & $\begin{array}{c}\text { Beta } \\
\text { alavancado } \\
\text { médio }\end{array}$ & $\begin{array}{c}\text { Correlação } \\
\text { média }\end{array}$ & $\begin{array}{c}\text { Beta } \\
\text { desalavancado } \\
\text { total }\end{array}$ & $\begin{array}{c}\text { Beta } \\
\text { alavancado } \\
\text { total }\end{array}$ \\
\hline metais e mineração & 1.589 & $\mathbf{1 , 0 7}$ & 1,43 & $13,86 \%$ & 7,69 & 10,33 \\
\hline
\end{tabular}

Fonte: Tabela desenvolvida pelo pesquisador com base no site Damodaran.

\section{Tabela 8: Beta da indústria}

O método utilizado para estimar o beta da Vale foi através do cálculo do beta desalavancado médio do setor de mineração, e alavancá-lo pela estrutura de capital da empresa. Os valores para o Beta de regressão tanto para a ADR quanto para a VALE foram obtidos no site do Damodaran e o Beta desalavancado do setor foi obtido pelos relatórios da corretora Ágora, os quais o pesquisador teve acesso. 


\begin{tabular}{|l|r|}
\hline Beta regressão VALEADR x S\&P500 & 1,25 \\
\hline Beta regressão VALE3 x Ibovespa & 0,91 \\
\hline Beta Desalavancado Setor & 0,91 \\
\hline Beta desalavancado global do setor & 1,07 \\
\hline Beta alavancado & 1,40 \\
\hline
\end{tabular}

Fonte: Tabela desenvolvida pelo pesquisador com base no sítio Damodaran.

Tabela 9: Beta alavancado

Para calcular o beta alavancado foi utilizada a fórmula:

$$
\beta a=\beta 0^{*}\left\{1-T^{*}[D /(C P)\}\right.
$$

Onde:

$\beta a=$ Beta alavancado

$\beta 0=$ Beta desalavancado

$\mathrm{T}=$ Alíquota de imposto (34\%)

$\mathrm{D}=$ Dívida financeira

$\mathrm{CP}=$ Valor de mercado do capital próprio

Para o cálculo do Beta Alavancado, utilizou-se a fórmula acima. Os valores utilizados em D, CP e T serão detalhados no cálculo do WACC.

$$
\beta a=1,07 *[1+(1-34 \%) * 47,55 \%]=1,40
$$




\section{- Taxa livre de risco}

Para determinação da taxa livre de risco é comum utilizar a taxa de retorno média de um título de dívida emitido pelo governo dos Estados Unidos.

A partir de dados do sítio do Damodaram, foi possível obter a média geométrica dos retornos anuais do T-bond 10 anos nos últimos 10 anos, valor esse utilizado no presente estudo como taxa livre de risco.

\section{$\mathrm{Rf}=\mathbf{4 , 8 8} \%$}

\section{- Prêmio de risco}

Há um consenso entre os profissionais de mercado de que a melhor maneira de se estimar o prêmio de risco é utilizando dados históricos. Para tanto, foi utilizada a metodologia padrão que consiste em calcular a diferença anual da média histórica dos retornos das ações em relação aos títulos públicos através de um período de tempo, podendo utilizar um prazo definido.

Nesse estudo foram utilizados os dados dos últimos 10 anos, tal como na determinação da taxa livre de risco.

Através do sítio do Damodaran, obtivemos a média geométrica dos retornos anuais do S\&P 500 e do T-Bond 10 anos nos últimos 10 anos, bem como o prêmio de risco, que é a diferença desses dois valores, tal como na tabela abaixo. O prêmio de risco então ficou definido como:

\begin{tabular}{|l|r|r|r|r|c|}
\hline Período & \multicolumn{5}{|c|}{ Média Geométrica } \\
\hline & S\&P 500 & 3-month T.Bill & 10-year T.Bond & Stocks - T.Bills & Stocks - T.Bond \\
\hline $\mathbf{1 9 2 8 - 2 0 1 4}$ & $9,60 \%$ & $\mathbf{3 , 4 9 \%}$ & $5,00 \%$ & $6,11 \%$ & $4,60 \%$ \\
\hline $\mathbf{1 9 6 5 - 2 0 1 4}$ & $9,84 \%$ & $4,99 \%$ & $6,70 \%$ & $4,84 \%$ & $3,14 \%$ \\
\hline $\mathbf{2 0 0 5 - 2 0 1 4}$ & $7,60 \%$ & $1,42 \%$ & $\mathbf{4 , 8 8 \%}$ & $6,18 \%$ & $\mathbf{2 , 7 3 \%}$ \\
\hline
\end{tabular}

Fonte: Tabela desenvolvida pelo pesquisador com base no sítio Damodaran. 


\section{$\mathrm{Rm}-\mathrm{Rf}=\mathbf{2 , 7 3} \%$}

\section{- Risco-Brasil}

O Risco-País é uma medida que visa classificar o risco geral de um país tendo como objetivo calcular o nível de instabilidade econômica de um país.

Como dito anteriormente será utilizado o $\mathrm{EMBI}+$ para medir a capacidade de um país honrar os seus compromissos financeiros. Quanto maior a pontuação do indicador de risco, mais perigoso fica a aplicar no país e este deve oferecer taxas de juros mais atrativas a fim de convencer os investidores a aplicarem seu dinheiro no empreendimento.

Como esse estudo é baseado em dados de dezembro de 2014 foi utilizado o EMBI+ Brasil de 30/12/2014, de acordo com o sítio do IPEA, o qual era de 261 pontos base.

$$
\mathbf{R p}=\mathbf{2 , 6 1 \%}
$$

\section{- Custo do capital próprio (ke)}

A partir dos dados e informações citadas foi possível calcular o custo do capital próprio, segundo a fórmula:

$$
\begin{aligned}
& \mathrm{Ke}=\mathrm{Rf}+\mathrm{B}^{\star}(\mathrm{Rm}+\mathrm{Rf})+\mathrm{Rp} \\
& \mathrm{Ke}=0,0488+\left(1,40^{\star} 0,0273\right)+0,0261 \\
& \mathrm{Ke}=11,31 \%
\end{aligned}
$$




\begin{tabular}{|l|r|}
\hline Taxa livre de risco & $4,88 \%$ \\
\hline Prêmio de risco & $2,73 \%$ \\
\hline Beta & 1,40 \\
\hline Risco Brasil & $2,61 \%$ \\
\hline Custo do Capital próprio nominal (US\$) & $11,31 \%$ \\
\hline
\end{tabular}

Fonte: Tabela desenvolvida pelo pesquisador.

Tabela 11: Custo capital próprio

- Custo de capital de terceiros (kd)

De acordo com dados extraídos das notas explicativas das Demonstrações Contábeis consolidadas em dezembro de 2014, o custo médio da dívida da Vale ficou em 5,62\% como mostra a Tabela 12. Os valores expressos na segunda coluna foram convertidos para reais e demostram a dívida de acordo com cada moeda.

\begin{tabular}{|c|c|c|c|c|}
\hline Empréstimos e financiamentos & Montante & Percentual & $\begin{array}{l}\text { Taxa de } \\
\text { juros média }\end{array}$ & $\begin{array}{c}\text { Taxa } \\
\text { ponderada }\end{array}$ \\
\hline Empréstimos e financiamentos em dólares & $\mathbf{R} \$ \mathbf{5 3 . 9 4 7}$ & $70,5 \%$ & $4,54 \%$ & $3,20 \%$ \\
\hline Empréstimos e financiamentos em reais & $\mathrm{R} \$ 16.750$ & $21,9 \%$ & $9,55 \%$ & $2,09 \%$ \\
\hline Empréstimos e financiamentos em euros & $\mathrm{R} \$ 5.036$ & $6,6 \%$ & $4,06 \%$ & $0,27 \%$ \\
\hline Empréstimos e financiamentos em outras moedas & $\mathbf{R} \$ 774$ & $1,0 \%$ & $6,24 \%$ & $0,06 \%$ \\
\hline Total (em milhões) & $\mathrm{R} \$ 76.507$ & $100 \%$ & & \\
\hline Custo médio da dívida & & & & $5,62 \%$ \\
\hline
\end{tabular}

Fonte: Tabela desenvolvida pelo pesquisador com base nos relatórios da Vale

Tabela 12: Custo médio da dívida 


\section{$W A C C=\mathrm{Ke}^{*}[\mathrm{CP} /(\mathrm{CP}+\mathrm{D})]+\mathrm{Kd}{ }^{*}(1-\mathrm{T}){ }^{*}[\mathrm{D} /(\mathrm{CP}+\mathrm{D})]$}

Onde:

$\mathrm{Ke}=$ Custo do capital próprio

$\mathrm{Kd}=$ Custo da dívida

$\mathrm{D}$ = Dívida financeira

$\mathrm{CP}=$ Valor de mercado do capital próprio

$\mathrm{T}=$ Alíquota de imposto (34\%)

Para o cálculo do capital próprio foi multiplicado as quantidades total das ações e ADRs em circulação em 30/12/2014 e suas respectivas cotações na mesma data. Como o cálculo foi feito em dólar, para as cotações das ações em real, dividimos o seu valor pela cotação do dólar no mesmo dia.

As quantidades de ações e ADRs da Vale em 30/12/2014 estão relacionadas na tabela abaixo, de acordo com o próprio sítio da companhia, bem como as respectivas cotações. A cotação do dólar foi extraída das notas explicativas das Demonstrações Contábeis consolidadas em dezembro de 2014 divulgadas pela empresa.

\begin{tabular}{|l|r|r|r|}
\hline & \multicolumn{1}{|c|}{ Ordinárias } & \multicolumn{1}{c|}{ Preferenciais } & \multicolumn{1}{c|}{ Total } \\
\hline Ações em circulação & 3.185 .653 .000 & 1.967 .721 .926 & 5.153 .374 .926 \\
\hline Ações em tesouraria & 31.535 .402 & 59.405 .792 & 90.941 .194 \\
\hline Total de ações & 3.217 .188 .402 & 2.027 .127 .718 & 5.244 .316 .120 \\
\hline ADRs & 800.208 .384 & 638.736 .050 & 1.438 .944 .434 \\
\hline & \multicolumn{3}{|l}{} \\
& \multicolumn{4}{|l|}{ Informações em 30/12/2014 } \\
\hline
\end{tabular}

Fonte: Tabela desenvolvida pelo pesquisador.

Tabela 13: Valor das ações e ADRs da Vale em 30/12/2014 
O valor da dívida (D) foi extraído das notas explicativas das Demonstrações Contábeis disponíveis no site da Vale, em dezembro de 2014.

\begin{tabular}{|l|c|}
\hline US\$ milhões & 2014 \\
\hline Dívida bruta & 28.807 \\
\hline Dívida Líquida (D) & 24.685 \\
\hline Dívida bruta / EBITDA ajustado & 2,20 \\
\hline EBITDA ajustado / pagamento de juros & 8,60 \\
\hline Dívida bruta/ EV (\%) & $43,8 \%$ \\
\hline
\end{tabular}

Fonte: Tabela desenvolvida pelo pesquisador com base nos relatórios da Vale.

Tabela 14: Indicadores de endividamento

$$
\begin{aligned}
& C P /(C P+D)=67,77 \% \\
& D /(C P+D)=32,23 \%
\end{aligned}
$$

Assim, pela fórmula do WACC apresentada anteriormente:

WACC $=0,1131^{\star} 0,6777+0,0562 *(1-0,34) * 0,3223=8,86 \%$

\begin{tabular}{|l|c|c|}
\hline & $\mathbf{2 . 0 1 5}$ & $\mathbf{2 . 0 1 6}$ \\
\hline Inflação EUA & $\mathbf{2 \%}$ & $\mathbf{2 \%}$ \\
\hline WACC nominal (US\$) & $8,86 \%$ & $8,86 \%$ \\
\hline Inflação Brasil & $8,1 \%$ & $5,3 \%$ \\
\hline WACC nominal (R\$) & $15,4 \%$ & $12,4 \%$ \\
\hline
\end{tabular}

Fonte: Tabela desenvolvida pelo pesquisador. 
Como a previsão da inflação brasileira de acordo com o Relatório Focus em maio de 2015, difere em seus valores para o ano de 2015 e 2016, adotou-se o WACC 2015 para descontar o fluxo de caixa do ano de 2015 e o WACC 2016 para descontar os demais fluxos futuros.

\subsection{Valor justo}

A partir das premissas estabelecidas e dos cálculos anteriores foi possível projetar os fluxos de caixa futuros e trazê-los a valor presente em 2014, obtendo o Valor da Empresa em 2014 além, do valor justo da ação, ou como o mercado nomeia, o valor alvo da ação para o final de 2015.

O valor encontrado foi comparado ao preço da ação em 31/12/2014, o que permite estimar o potencial da variação do papel.

\begin{tabular}{|l|r|r|r|r|r|r|r|r|}
\hline & $\mathbf{2 0 1 5}$ & $\mathbf{2 0 1 6}$ & $\mathbf{2 0 1 7}$ & $\mathbf{2 0 1 8}$ & $\mathbf{2 0 1 9}$ & $\mathbf{2 0 2 0}$ & $\mathbf{2 0 2 1}$ & $\mathbf{2 0 2 2}$ \\
\hline Receita Bruta & 99.074 & 95.577 & 106.488 & 119.785 & 127.571 & 135.863 & 144.695 & 154.100 \\
\hline (-) Deduções da Receita Bruta & 1.801 & 1.739 & 1.921 & 2.161 & 2.302 & 2.451 & 2.611 & 2.780 \\
\hline (=) Receita líquida & 97.273 & 93.838 & 104.567 & 117.624 & 125.270 & 133.412 & 142.084 & 151.319 \\
\hline (*)Margem EBIT & $37,32 \%$ & $37,32 \%$ & $37,32 \%$ & $37,32 \%$ & $37,32 \%$ & $37,32 \%$ & $37,32 \%$ & $37,32 \%$ \\
\hline (=) EBIT & 36.306 & 35.024 & 39.028 & 43.902 & 46.755 & 49.795 & 53.031 & 56.478 \\
\hline (-) Aliquota de IR & $15,93 \%$ & $15,93 \%$ & $15,93 \%$ & $15,93 \%$ & $15,93 \%$ & $15,93 \%$ & $15,93 \%$ & $15,93 \%$ \\
\hline (=) EBIT * (1-IR) & 30.524 & 29.446 & 32.813 & 36.910 & 37.648 & 38.401 & 39.169 & 39.953 \\
\hline (+) Depreciação & 8.524 & 8.996 & 9.145 & 9.193 & 8.965 & 9.075 & 9.094 & 9.082 \\
\hline (-) Capex & 15.236 & 15.236 & 15.236 & 15.236 & 15.236 & 15.236 & 15.236 & 15.236 \\
\hline (-) Variação NCG & 1.082 & 1.199 & 1.395 & 1.638 & 1.494 & 1.529 & 1.550 & 1.553 \\
\hline (=) Fluxo de caixa da empresa & 22.729 & 22.006 & 25.326 & 29.228 & 31.543 & 34.174 & 36.893 & 39.776 \\
\hline Fator de desconto & 1,15 & 1,33 & 1,53 & 1,77 & 2,047 & 2,36 & 2,73 & 3,15 \\
\hline (=) Valor Presente FCL & 19.696 & 19.606 & 20.524 & 21.515 & 16.634 & 14.855 & 13.089 & 125.106 \\
\hline
\end{tabular}

Fonte: Tabela desenvolvida pelo pesquisador

Tabela 16: Fluxo de caixa livre projetado 


\begin{tabular}{|c|c|}
\hline Avaliação & \\
\hline Valor presente do FCL & $\mathrm{R} \$ 122.653 .012 .999,94$ \\
\hline Valor presente da perpetuidade & $\mathrm{R} \$ 125.106 .073 .259,94$ \\
\hline (=) Valor da empresa & $R \$ 247.759 .086 .259,88$ \\
\hline (+) Caixa & $\mathrm{R} \$ 10.555 .000 .000,00$ \\
\hline (-) Dívida & $-R \$ 81.101 .000 .000,00$ \\
\hline (-) Valor das ações PN & -R\$ 37.839.292.636,98 \\
\hline$(-)$ Valor das ADRs & -R\$ 29.931.447.754,30 \\
\hline (=) Capital próprio & $\mathrm{R} \$ \mathbf{1 0 9 . 4 4 2 . 3 4 5 . 8 6 8 , 6 0}$ \\
\hline Número de ações & 3.185 .653 .000 \\
\hline Valor por ação & $\mathrm{R} \$ 34,35$ \\
\hline Cotação (30/12/2014) & $\mathrm{R} \$ 21,91$ \\
\hline Variação do valor encontrado & $5678,00 \%$ \\
\hline WACC 2015 & $15,40 \%$ \\
\hline WACC 2016 & $12,38 \%$ \\
\hline Taxa de crescimento na perpetuidade & $2 \%$ \\
\hline
\end{tabular}

Fonte: Tabela desenvolvida pelo pesquisador com base nos relatórios da Vale.

Tabela 17: Avaliação 


\section{Conclusões e recomendações para novos estudos}

Este trabalho teve como objetivo principal verificar se o valor de mercado da empresa, ao final de 2014, estava coerente com o valor das ações ordinárias nessa época.

Levando em consideração o referencial teórico, as premissas estabelecidas no presente estudo e os cálculos efetuados para estimar o valor justo das ações da Vale, foi encontrado o valor de $\mathrm{R} \$ 34,35$ para as ações da mineradora. Esse valor, preço alvo do ativo para 2015, apresenta uma valorização sobre a cotação da VALE3 no ultimo dia do ano passado, $R \$ 21,91$.

Assim, levando em conta os valores obtidos neste trabalho, a recomendação para as ações VALE3 seria de compra. Porém chama a atenção a diferença entre os valores levantados no presente estudo com o real valor desse ativo.

Possíveis motivos para essa diferença de valores são das taxas de crescimento adotadas estarem atualmente superiores às previstas pelos investidores devido ao atual cenário. A elevação da inflação acumulada no ano de 2015 e o aumento da inflação esperada para 2016 afetam as projeções e cálculos feitos para encontrar o valor das ações. Eventuais impactos cambiais, que afetam a receita e dívidas da empresa também não foram levados em conta.

O impacto das indefinições políticas e econômicas do país, que evoluíram para as crises vivenciadas em 2015, que teve por consequência à perda de grau de investimento das empresas brasileiras. Este fato, também modificaram as projeções e especulações feitas pelo mercado e por analistas também impactaram no valor das ações.

Mesmo com a alteração do cenário em que a Vale atua, foi possível, de acordo com as projeções realizadas no capítulo 5, atender os objetivos 
intermediários propostos neste estudo, como analisar os preços históricos dos insumos e seus respectivos impactos na receita da Vale.

Após atender o objetivo citado a cima, foi possível realizar as premissas e delimitações ao estudo de analise exclusivamente o minério de ferro, principal área de atuação da empresa. Assim, o cenário no qual a Vale está inserida foi analisado, verificando as principais vantagens e desvantagens deste setor.

Com base nos indicadores financeiros disponíveis nos sítios citados ao longo deste trabalho, foram feitas projeções de crescimento esperado para empresa mesmo que atualmente este esteja divergente do valor de mercado devido a mudanças no cenário brasileiro, após foi realizado o cálculo do beta da empresa e por fim através do método de Fluxo de Caixa Descontado, encontrar o valor justo para as ações da mineradora.

Ao iniciar o estudo proposto era esperado encontrar que as ações da companhia estavam sobrevalorizadas, pois o preço do minério se encontrava em baixas históricas, porém com os estudos realizados foi possível verificar que a longo prazo a empresa deve ter uma valorização no preço das suas ações.

A diferença entre o valor encontrado e o valor atual do ativo pode ser decorrente de fatores diversos, tais como a variação do dólar, o atual cenário econômico Brasileiro ou ainda a perspectiva de perda do grau de investimento, o que de fato ocorreu recentemente em 2015. Outros fatores não econômicos podem também estar influenciando a cotação da VALE3.

Assim, futuros trabalhos podem focar na análise dos fatores econômicos ou não econômicos que estariam levando à significativa diferença encontrada para o valor da empresa.

Especificamente com relação a este estudo, sugere-se complementá-lo com a avaliação da empresa por outros métodos, tais como Modelo de Fluxo de Dividendos Descontados e o Método de Múltiplos de Mercado. 


\section{Referências bibliográficas}

ÁGORA CORRETORA. Laudo de Avaliação de Aquisição de Ações Ordinárias e Preferencias. Rio de Janeiro, 2014.

ASSAF NETO, A.; Finanças Corporativas e Valor; São Paulo: Atlas; 2003.

ASSAF NETO, A. Contribuição ao estudo da avaliação de empresa no Brasil: uma aplicação prática. Ribeirão Preto, São Paulo: Universidade de São Paulo, 2004.

BANCO CENTRAL. Banco Central do Brasil, acesso entre 03 de março de 2015; 02 de maio de 2015.

Disponível: http://www.bcb.gov.br

CAMPOS, A. F. Demonstração dos fluxos de caixa: Uma ferramenta indispensável para administrar sua empresa. São Paulo: Atlas, 1999.

COOPELAND, Tom; KOLLER, Tim; MURRIN, Jack. Avaliação de empresasvaluation: calculando e gerenciando o valor das empresas. $3^{\underline{a}}$ ed. São Paulo: Pearson Education, 2002.

CostA, L. G. T. A; CostA L. R. T. A; ALVIM, M. A, Valuation: manual de avaliação e reestruturação econômica de empresas. São Paulo: Atlas 2010.

DAMODARAN, A. A; Face oculta da avaliação; São Paulo: Makron Books; 2002.

DAMODARAN, A. A; Avaliação de Investimentos. Rio de Janeiro: Makron Books; 1999.

DAMODARAN, A. A.; acesso entre 03 de março de 2015; 02 de maio 2015.

Disponível: http://pages.stern.nyu.edu/ adamodar/ 
ECO, H; Como se faz uma tese. 25 $5^{\text {a }}$ ed. São Paulo: Perspectiva;2014

FALCINI, P. Avaliação econômica de empresas: técnica e prática. São Paulo: Atlas, 1995.

GIL, A.C.; Como Elaborar Projeto de Pesquisa; São Paulo: Atlas, 2002.

GITMAN, Lawrence J. Princípios de Administração Financeira. $7^{a} \underline{\text { ed. São }}$ Paulo: Harbra, 1997.

GITMAN, J. L.; Princípios de administração financeira. Tradução de Allan Vidigal Hastings. 12 ed. São Paulo: Pearson Prentice Hall, 2012.

IPEADATA: acesso entre 03 de março de 2015; 02 de maio 2015.

Disponível: http://www.ipeadata.gov.br

MARTINS, E. Avaliação de Empresas: da mensuração contábil à econômica. São Paulo: Atlas, 2001.

MARTELANC, R. C. F; PASIN, R; PEREIRA, F. Avaliação de empresas. 1 ed. São Paulo; Pearson. 2005.

NEVES, B. M. Gabriel; Uma avaliação da H. J. Heinz Company. Rio de Janeiro, 2015. Trabalho de Conclusão de Curso (Graduação em Administração, PUC-Rio).

PÓVOA, Alexandre. Valuation - Como precificar ações. $2^{\underline{a}}$ ed. São Paulo: Globo, 2007.

ROSS, S. A., WESTERFIELD, R. W., JORDAN, B. D., LAMB, R.; Fundamentos de Administração Financeira; Porto Alegre: AMGH Editora Ltda.; 2013

SAMANEZ, C. P.; Gestão de Investimento; São Paulo: Pearson Prentice Hall; 2007. 
Vale S.A. Relatórios (Demonstrações contábeis, Relatórios Anuais, Capex, Livro Vale - Nossa História, etc.) disponibilizados no sítio da empresa, Disponível: http://www.vale.com/PT/investors/information-

market/PressReleases/ReleaseDocuments/vale IFRs BRL 4t14p.pdf 